\title{
CRIME E SUBJETIVIDADE: \\ REFLEXÃO SOBRE OS DISCURSOS E AS PRÁTICAS LEGITIMADORES DO EXERCÍCIO DISCRIMINATÓRIO DO DIREITO PENAL
}

\author{
CRIME AND SUBJECTIVITY: REFLECTIONS ON THE DISCOURSES AND \\ PRACTICES OF LEGITIMIZING DISCRIMINATORY EXERCISE OF CRIMINAL \\ LAW
}

\author{
Farah de Sousa Malcher ${ }^{1}$ \\ Jean-François Yves Deluchey ${ }^{2}$
}

\section{RESUMO}

Defendemos a importância de estudar o tratamento discriminatório do direito penal a partir da análise dos discursos sobre as subjetividades, resultantes na dicotomia cidadão/inimigo. Racionalizações acerca da categoria do inimigo nas chamadas "sociedades do risco", parecem justificar o exercício desigual do poder punitivo e a neutralização de indivíduos rotulados como nocivos e desviantes, ainda que em detrimento dos princípios, direitos e garantias fundamentais do Estado de Direito. Tais discursos também favorecem o ambiente neoliberal, na medida em que traduzem toda a conflitividade social em punição e legitimam processos estigmatização, criminalização da pobreza e seletividade penal.

Palavras-chave: Discursos; Subjetividade; Cidadão; Inimigo; Neoliberalismo.

\begin{abstract}
We defend the importance of studying the discriminatory treatment of criminal law from the analysis of discourses on the subjectivities, resulting in dichotomy citizen/enemy. Rationalisations about the category of enemy in so-called "law of risk", seem to justify the unequal exercise of power punitive and the neutralization of individuals labelled as harmful and abnormal behavior, even if this is at the expense of principles, fundamental rights and guarantees of the rule of law. Such discourses also favors the neoliberal environment, to the extent that translate the entire conflitividade on punishment and legitimized stigmatization processes, criminalization of poverty and criminal selectivity.
\end{abstract}

Keywords: Discourses; Subjectivity; Citizen; Enemy; Neoliberalism.

\footnotetext{
${ }^{1}$ Doutoranda do Programa de Pós-Graduação em Direito da Universidade Federal do Pará. Pesquisadora do Centro de Estudos sobre Instituições e Dispositivos Punitivos - CESIP. Analista Judiciário do TJPA. Pará (Brasil). E-mail: fsmalcher@gmail.com

${ }^{2}$ Docente permanente do PPG em Direito da UFPA. Doutor em Ciência Política/Políticas Públicas na Universidade da Sorbonne Nouvelle-Paris 3. Pesquisador/visitante do IPEA. Coordenador do CESIP. Pará (Brasil).
} 


\section{INTRODUÇÃO}

A admissibilidade do conceito de inimigo nos discursos e nas práticas do direito penal brasileiro e a constante dialética entre Estado de direito e Estado de polícia que se observa naquele campo, e que se reflete pela admissão mais ampla ou mais restrita do tratamento punitivo a seres humanos privados da condição de pessoas, faz emergir questionamentos quanto à lógica do poder punitivo nas democracias neoliberais.

O exercício cada vez mais discriminatório do direito penal, que divide a sua clientela na dicotomia cidadão/inimigo, parece encontrar amparo em um arcabouço de discursos e saberes ditos científicos, que por sua vez, têm justificado e legitimado a exclusão/punição dos indesejáveis, ainda que em detrimento de direitos mais fundamentais como a vida e a dignidade humana, calcado no risco e/ou perigo que representam aos cidadãos de bem dentro do contrato social.

Diante deste panorama, acreditamos ser preciso desvelar a relação que se estabelece entre discursos/saberes, práticas de poder e o direito penal no tocante à categorização de certos indivíduos como inimigos do Estado, e de como esse processo legitima a existência de um direito penal desigual, fundado no conceito de personalidade.

Ao que parece, o exercício estruturalmente discriminatório do poder punitivo, o qual confere a certos seres humanos considerados entes perigosos ou daninhos, tratamento não condizente com a condição de pessoas, autoriza o Estado a negar-lhes o direito de terem suas infrações sancionadas dentro dos limites do direito penal liberal e das aclamadas garantias universais dos direitos humanos.

Para Zaffaroni (2006), tal tratamento provoca uma fissura absolutista no Estado constitucional, implicando no abandono do princípio do Estado de direito em favor do Estado absoluto. E as leis, a doutrina jurídica e os saberes sobre a conduta humana legitimam esse tratamento diferenciado, atribuindo-lhe justificativa científica, pois o direito penal, ao admitir que alguns seres humanos são perigosos e que por isso precisam ser eliminados, coisificou-os, ocultando este fato com discursos que racionalizam a categoria do inimigo e, com isso, legitimando ou postulando o genocídio direto dos indesejáveis.

$\mathrm{O}$ autor defende a tese de que a presença do ente perigoso no direito penal é de caráter político, não se podendo deixar de invocar Hobbes e a questão da soberania. Prova disso é que 
cada vez mais se discute se é possível tratar seres humanos de acordo com o perigo ou dano que representam ao contrato social.

A justificativa para o tratamento penal diferenciado é a negação jurídica da condição de pessoa ao inimigo, como se fosse uma espécie à parte do gênero humano. Do paradigma da inferioridade biológica, decorre a inferioridade jurídica. Mas não é qualquer infrator o inimigo, e sim aquele que ameaça o Estado soberano, autor de crimes de alta traição, o inimigo político cujos conflitos não podem ser decididos por um sistema de normas.

É aquele que assume uma atitude de insubordinação jurídica intrínseca, ou, nas palavras de Cirino dos Santos (2012-p. 5): "uma base subjetiva real capaz de produzir um estado de guerra contra a sociedade, com a permanente frustração das expectativas normativas [...] perdendo a qualidade de pessoa portadora de direitos, porque desafia o sistema social”.

O inimigo é punido em razão do "ser", do existir como ente perigoso, mediante um forte movimento para o direito penal do autor, o que autoriza a sua punição pela privação ampla ou restrita de direitos mais elementares, sobretudo, de sua liberdade, por medidas diferentes do que se possa chamar de pena para o direito penal do Estado de direito. A pena para o inimigo é mera contenção, uma espécie de enjaulamento cuja finalidade é o impedimento ou a eliminação física.

Na medida em que o tratamento como "coisa perigosa" tem como justificativa o não reconhecimento da condição de pessoa, importante, em meio à problemática levantada neste artigo, estudar a questão do sujeito, isto é, as condições históricas, políticas e econômicas que permitiram o aparecimento de discursos (saberes) responsáveis pela categorização de sujeitos como perigosos, como se deu a construção desses discursos que antecederam as leis, as instituições e as práticas discursivas ${ }^{3}$ do direito penal, e de como estas, por sua vez, foram capturadas por esse discurso.

A noção cartesiana de loucura como desrazão trazida por Foucault (2012) em a História da Loucura, na qual relata o exato momento em que a loucura foi excluída da ordem da razão, cingiu os sujeitos entre as categorias fixas do normal e anormal. $\mathrm{O}$ louco, assim como o infrator e todos os demais heterogêneos que ameaçavam o Estado soberano, foram associados aqueles que, de alguma forma, transgridem as normas morais, sociais e jurídicas.

\footnotetext{
${ }^{3}$ Por práticas discursivas, compartilho da noção de Foucault (2000), para o qual tais práticas referem-se a processos de produção de sentidos. Enquanto os discursos são condições de possibilidade para a existência das relações de saber/poder, as práticas discursivas ultrapassam os limites do ato de falar e de pronunciar uma fala, exteriorizandose como uma prática produtora de sentidos e que os faz circular.
} 
Formou-se uma consciência médico-jurídica da loucura e do crime, associada à incapacidade da pessoa como sujeito de direito, titular de direitos e obrigações. O louco e o criminoso são percebidos a partir de uma referência fundamental ao sujeito de direito. $\mathrm{O}$ infrator representa a alienação do sujeito de direito, marcado pelo reconhecimento jurídico de sua irresponsabilidade e de sua incapacidade como sujeito de obrigações, dentro de uma ordem social dada.

Por outro lado, o advento da Era Moderna marcou a ascensão do homem como único ser dotado de razão, capaz de pensar e de racionalizar seus desejos, assim como, de autodeterminar sua vontade em torno de um imperativo moral, universal e categórico, inspirado no modelo da norma jurídica.

O sujeito autônomo capturado pela filosofia moderna, de Descartes a Kant, acabou por aprisionar as subjetividades humanas à estrutura fixa e absoluta do sujeito moral e racional, capaz de orientar suas ações em torno de um dever-ser que bastante lembra a norma jurídica. Por seu turno, todos aqueles que não se adaptavam à imagem do sujeito moderno foram identificados como anormais, patológicos e imorais, como é o caso do louco, do criminoso, do menor infrator, do usuário de drogas, do mendigo, do homossexual e de toda a espécie de degenerados que viviam à margem do Estado Moderno.

Diante do problema do exercício discriminatório do poder punitivo nas democracias neoliberais, e da adesão, cada vez mais ampla, do conceito de inimigo na doutrina e nas práticas do direito penal, faz-se imprescindível compreender os processos pelos quais os sujeitos foram nomeados perigosos, entendendo que sujeito, conforme nos ensina Foucault (1995), é produto de uma trama histórica, atravessada por relações de saber/poder, em que aparece como resultado de uma operação de assujeitamento a um dispositivo, que ao mesmo tempo em que enuncia uma verdade sobre ele, liga-o coercitivamente a uma determinada identidade (louco/são, inimigo/cidadão, sujeito/coisa), de forma a subjugá-lo.

Mas a questão da produção dos sujeitos perigosos e do direito penal enquanto dispositivo de poder a serviço deste processo, precisa ser pensada paralelamente ao contexto do neoliberalismo enquanto terceira era da governamentalidade, em que a segurança assume o papel de favorecimento das trocas e da garantia da livre participação no jogo econômico.

Para Batista (2011), o neoliberalismo tornou o sistema penal o território sagrado da nova ordem sócio-econômica, pois se a política não tem como reduzir a violência e as desigualdades que o modelo econômico produz, ela precisa mais do que um discurso, precisa de um espetáculo. 
Por consequência, se sobram braços e corpos no mercado de trabalho, aumentam os controles violentos sobre a vida dos pobres. O neoliberalismo promove a policização da política através da ascensão do Estado Penal, correspondente ao desmonte do Estado Previdenciário, onde o importante é traduzir toda a conflitividade social em punição.

Ante a breve problematização exposta, pretendemos, neste artigo, chamar atenção para a necessidade de se produzir pesquisas que visem à compreensão do exercício discriminatório do poder punitivo nas sociedades democráticas a partir da investigação dos discursos acerca das subjetividades.

É preciso levantar as condições de produção e os efeitos dos sentidos impostos por discursos/saberes acerca dos sujeitos perigosos, e sua relação com as práticas de poder, buscando identificar quais as racionalidades que legitimam o exercício discriminatório do poder punitivo. Defendemos que a compreensão de tal questão perpassa pelo problema crime e subjetividade, o qual devemos enfrentar.

\section{CRIME E PRODUÇÃO DE SUBJETIVIDADE}

Desde as últimas décadas do século XX, observa-se o aumento da preocupação social com a violência e o expressivo avanço do sentimento de insegurança coletiva. A sociedade brasileira questiona a eficácia das políticas criminais e de segurança pública e dos meios de controle social, como o direito penal.

O combate eficaz à criminalidade parece estar associado à adoção de medidas punitivas mais rigorosas, ainda que degradantes da dignidade humana, tudo em nome da defesa e da paz social. Nesse cenário de medo e intolerância, em que se observa um movimento de insegurança generalizada em face do futuro, proliferam discursos respaldados por saberes científicos, no sentido de definir uma noção e uma imagem fixa do risco e do perigo, que justifiquem e legitimem mecanismos de prevenção e de repressão às ameaças sociais.

Castel (2005) associa o sentimento de insegurança social ao enfraquecimento do Estado nacional-social em meados dos anos 70 , pois com a fragilização dos sistemas de seguridade clássicos, emergiu uma nova geração do risco, uma espécie de proliferação ou cultura do perigo, em que o essencial não é mais o progresso social, mas o princípio geral de incerteza que comanda o futuro da civilização. 
Ao mesmo tempo em que a insegurança tornou-se o horizonte intransponível da condição do ser humano moderno, o modelo de sociedade que se impôs é o de um conjunto de grupos homogêneos, que sob o clamor da insegurança, promove a crescente "dessocialização" de indivíduos rotulados como heterogêneos, entregues a si e à sua inutilidade, em virtude da degradação do vínculo social e da perda de homogeneidade que lhes permite constituir-se como atores sociais de plenos direitos.

A “dessocialização" ou "descoletivização" de certos indivíduos, segundo Castel, constitui-se em poderoso fator de insegurização e de produção de representações sociais do risco, em uma espécie de condenação moral que condensa e simplifica a problemática global da insegurança, e toda a complexidade do conjunto de problemas situados à origem do sentimento de insegurança, tais como, desemprego, desigualdades sociais, racismo, entre outros.

Wacquant (2010) denomina de "governo da insegurança social" o novo modelo de gestão da miséria deflagrado nos Estados Unidos para dar conta dos processos concomitantes de desregulação econômica e de redução da assistência social no final do século XX. O retributivismo e o positivismo quanto ao caráter patológico do crime, voltam à cena com o fim do Welfare Estate. É que o paradigma do Estado keynesiano não deu mais conta das mudanças e desigualdades impostas pelo neoliberalismo.

Relaciona a evolução do poder punitivo ao sucesso do neoliberalismo e ao desenvolvimento de políticas de segurança ativas e punitivas circunscritas à delinquência de rua e às categorias situadas às margens da nova ordem econômica. Tais políticas, para Wacquant (2001), são objeto de um consenso político e de uma ampla aceitação pública que confunde criminalidade, pobreza e insegurança, em que a figura do delinquente é utilizada para canalizar uma série de transformações conexas como mudanças de salários, crise da família patriarcal, competição escolar como meio de acesso ao emprego, entre outras. A severidade penal é apresentada como uma necessidade saudável e indispensável à autodefesa do corpo social ameaçado pela criminalidade.

Jovens desempregados, dependentes químicos, refugiados e outros grupos "à deriva”, tornam-se presenças indesejáveis e intoleráveis no espaço público, pois são a encarnação viva e ameaçadora da insegurança generalizada, promovida pelo paradigma do emprego e do salário estável e homogêneo, trazendo a prisão e os dispositivos de encarceramento de volta à cena principal da sociedade. 
Nesse contexto, proliferam discursos acerca das subjetividades antissociais, resultando em aumento da seletividade penal, estigmatização e criminalização da pobreza. Tal processo é reforçado pelo o que Batista (2012) denomina de "adesão subjetiva à barbárie", em que a grande mídia, através de um "populismo criminológico", inculca o desejo de punir no senso comum e incentiva a crescente demanda coletiva por castigo e punição, produzindo as identificações necessárias do perigo, pois, para que aconteça o extermínio dos inimigos, necessário o discurso legitimante.

Enquanto a questão criminal encobre a compreensão da conflitividade social, o neoliberalismo se constrói às custas de uma gigantesca "indústria de controle do crime" que, segundo Batista, produz subjetividades e assujeitamentos ao direcionar o poder punitivo aos pobres, olhados cada vez mais como inimigos e (2012-p. 5): “jogados para fora dos afetos e gastos do Leviatã patriarcal".

Para Deluchey e Brito (2013), a especificidade no tratamento público da segurança na ordem democrática brasileira, também consiste em inculcar no senso comum ações governamentais repressoras, como se políticas de segurança pública estivessem restritas, exclusivamente, a políticas de combate à criminalidade, retirando qualquer possibilidade de contextualizar o tratamento da criminalidade a partir de políticas de cunho social, em uma perspectiva mais ampla que a policial.

É que o ambiente neoliberal oferece maior possibilidade de expressão à formação de um sistema democrático de segurança pública, fundamentado, exclusivamente, no recrudescimento da repressão criminal, em especial, dirigida às classes pobres, o que inibe qualquer capacidade de autorreflexão e de liberdade política, estimulando a formação de um discurso popular (e midiático), que sob o eco da insegurança social e da promoção do medo, dissimula seus efeitos de exclusão e de controle da população.

O novo homem racional da era neoliberal deve ser capaz de antecipar os riscos por meio de uma gestão controlada do risco, o que explicaria, na contemporaneidade, a proliferação de rótulos acerca das subjetividades, ou, nas palavras de Ribeiro (2013, p. 182): "a dissecação mais detalhada, mais profunda do coração humano; e mais ainda, do coração do criminoso (pois o perigo e o risco são intoleráveis)"”.

Acerca da definição do desvio e do comportamento desviante, Becker (2009) afirma que o desvio é resultado de um amplo processo de interação de interesses entre as pessoas que criam o comportamento desviante e as pessoas que impõem ou executam as regras destinadas aos 
desviantes. Para ele, grupos sociais dominantes, por meio de regras, pontuam e determinam as estruturas. E quando uma regra imposta é infringida, os infratores são vistos como um tipo especial, um outsider, alguém que está do lado de fora do grupo, do círculo dos "normais", para além das margens delimitadas pelo limite ou fronteira social.

Afirma que é a própria sociedade que cria o desvio e o desviante, de acordo com seus interesses. Chama atenção para o modo como um grupo conquista e usa o poder de definir como outros grupos serão compreendidos e tratados, mantendo, assim, o controle sobre o modo como as pessoas definem o mundo. O desvio e o desviante são consequências do processo de interação entre as pessoas que criam e impõem regras, muitas vezes, a serviço de seus próprios interesses.

Nas palavras de Zaffaroni (2006, p. 23): "Trata-se de inimigos declarados, não porque declarem ou manifestem sua animosidade, mas sim porque o poder os declara como tais".

Mas a questão do desvio e do comportamento desviante, ainda conforme Becker (2010), também está relacionada ao universo das representações sociais que permeiam a sociedade, isto é, às maneiras pelas quais algumas pessoas contam o que pensam saber para outras. As representações da sociedade são verdadeiros produtos organizacionais, que dividem as pessoas entre produtores e usuários de representações.

Qualquer representação da realidade social é necessariamente parcial, pois é menos do que experimentaríamos caso resolvêssemos interpretá-la conforme o contexto real que representa. Esse seria o sentido das representações: relatar somente aquilo que os usuários precisam para os fins por eles almejados. Os mundos representacionais, assim, diferem de acordo com o conjunto de interesses dominantes e as representações incorporam as escolhas e os interesses dos produtores.

A partir do pensamento de tais autores, defendemos a necessidade de se produzir pesquisas acerca do exercício discriminatório do direito penal associado à questão do sujeito, a fim de desvelar os discursos os quais permitiram que, em determinado contexto histórico, pessoas fossem nomeadas e tratadas como perigosas pelo poder punitivo.

\subsubsection{Normalização e Direito: separação entre sujeitos e não-sujeitos}

O filósofo francês Michel Foucault (1995), em seus estudos acerca dos processos de produção de subjetividade, refuta a ideia de universalidade que circunda a noção moderna de sujeito, compreendido como ser essencial e absoluto. Rompe com a ideia de sujeito enquanto 
essência, substância, ente. Desconstrói o sujeito tradicionalmente concebido na Modernidade como forma fixa e imutável, dotado de razão, como o "eu pensante" cartesiano, o sujeito absoluto e totalizado, autônomo e autossuficiente, o homem soberano da filosofia iluminista.

Em seu projeto filosófico, traçou uma história da subjetividade paralelamente às formas de governamentalidade, tendo como ponto de partida as separações operadas na sociedade em nome da loucura, da delinquência, da sexualidade e em torno da constituição de um sujeito racional e normal. A subjetividade foucaultiana é entendida como uma experiência histórica e coletiva, construída a partir de uma multiplicidade de práticas sociais. $\mathrm{O}$ foco de análise passa do sujeito às práticas sociais.

Ao sentido de sujeito, atribui dois significados distintos, porém correlatos: 1) Quem se sujeita a alguém, pelo controle e dependência. 2) De sujeito preso à sua própria identidade, por uma consciência ou autoconhecimento, sendo que, para Foucault (1995, p. 235): "ambos sugerem uma forma de poder que subjuga e torna sujeito a".

Sob a perspectiva do sujeito foucaultiano, podemos inferir que o indivíduo rotulado como perigoso pelo direito penal não deve ser compreendido como algo já dado, como substância em vez de forma, ou ainda mera representação do social a qual naturalizamos e reproduzimos como se fosse uma verdade. Antes, é preciso indagar as condições de produção desse sujeito como condições de possibilidade, que permitem o surgimento de um modo de subjetivação específico.

Para este estudo, as noções de "norma" e "normalização" em Foucault são de suma importância, pois estão associadas ao campo dos saberes, das ciências que têm por objeto a vida, tais como a medicina, a psiquiatria, a psicologia e o direito, e que implicaram na formação da subjetividade moderna. A "norma" caracteriza a forma que determinados saberes assumiram na modernidade, tendo como traço distintivo o caráter normalizador que define e separa os sujeitos por eles estudados nas categorias do normal/anormal. É por isso que o tema da norma em Foucault aparece intrinsecamente relacionado à descoberta da loucura e de sua categorização como doença pela psiquiatria, na medida em que, a partir daí, se instituiu um critério de classificação e de separação das subjetividades.

Em a História da Loucura, Foucault (2012) nos mostra que a condição histórica de possibilidade dos objetos de saberes como a medicina, a psiquiatria e o direito, não foi outra senão o homem enquanto sujeito racional, marcado em sua finitude. E a norma, nesse contexto, foi o componente do modo de ser dos saberes classificados como ciências humanas na Modernidade. 
Para Fonseca (2002), naquela época, tais saberes normatizaram as funções do homem como ser vivente, de modo a regulamentar os conflitos aos homens inerentes e a sistematizar as significações do homem que se expressa pelas diversas formas da linguagem. No interior desses saberes, a norma possui duas instâncias: uma negativa, que permite, com base no critério do normal/patológico, separar sujeitos; e a positiva, que se especifica conforme estratégias, mecanismos e tecnologias positivas de poder resultantes na constituição de sujeitos.

Os procedimentos de normalização, em suma, não implicam unicamente em exclusão ou repressão. Tendo como foco os processos inerentes à vida, têm como forma de atuação uma biopolítica e implicam em uma certa arte de governar. É que as práticas discursivas consubstanciadas em saberes normalizadores, tais como a medicina, a psiquiatria e a ciência jurídica penal, que permitem segregar e constituir sujeitos, não são independentes das práticas de poder, mas antes, constituídas por estas.

A norma, nesse sentido, é um mecanismo de intervenção do poder que se exerce através de mecanismos de normalização (disciplinantes e biopolíticos). Não pode ser remetida, tão somente, à ideia de restrição ou exclusão, mas, sobretudo, à imposição de limites por meio de uma ordem do normal, do aceitável e do desejável, de forma a engendrar a produção das condutas esperadas. A normalização produz condutas, gestos, discursos e sujeitos.

Neste cenário, importante pensar nas implicações decorrentes entre direito e norma e em que medida o direito penal atua como vetor de normalização, ao passo em que ele mesmo é normalizado. Para tal, importante desatrelar a análise do direito única e exclusivamente do modelo jurídico-discursivo - em que aparece como lei pura, regra de proibição que divide o lícito do ilícito, o legítimo do ilegítimo, o justo do injusto - para também raciociná-lo através da normalização, enquanto modelo de poder que produz relações de força na constituição de saberes e sujeitos, dentre estes, o inimigo ou sujeito perigoso.

$\mathrm{Na}$ investigação sobre o exercício desigual do direito penal, calcado na produção de discursos/saberes que sustentam a existência de sujeitos perigosos, acreditamos ser preciso desviar o foco da noção conceitual do direito e privilegiar sua análise no plano das práticas sociais, entendendo que lei e normalização não podem ser pensadas de maneira independente. Não se tratam de planos contraditórios, mas complementares. O "legal” e o "normal” com suas mútuas implicações na constituição dos sujeitos, na normalização das condutas e na configuração de enquadramentos normativos-punitivos específicos. 
Sob tal ótica do direito, defendemos também a importância de estudar o inimigo nos discursos criminológicos, responsáveis pela transformação do crime em doença e pela patologização do infrator, criando uma certa "mentalidade criminológica" e justificando um direito penal desigual.

\subsubsection{Discursos criminológicos}

De acordo com Rauter (2003), os efeitos do discurso criminológico deixaram marcas indeléveis nos modos de proceder dos técnicos do sistema penal, que resultaram no reaparelhamento do Judiciário, ampliando seus dispositivos de controle e repressão. Criou-se toda uma estrutura de diagnóstico psicológico do criminoso, baseada em uma tecnologia do preconceito, respaldada por instrumentos técnico-científicos (laudos psicológicos, psiquiátricos, sociais, etc.), cujo efeito concreto é o aumento puro e simples da pena.

Acerca da discriminação no exercício do poder punitivo, Zaffaroni (2006) afirma que se trata de uma constante derivada de sua seletividade estrutural, pois a história demonstra que os rótulos caíram sobre estereótipos muito diferentes, de acordo com a hegemonia discursiva e a perspectiva daqueles que detiveram o poder.

A este fenômeno, atribui uma hipótese geral, subdividida da seguinte forma: 1) O poder punitivo sempre foi discriminatório, na medida em que conferiu a certos seres humanos tratamento não condizente com a condição de pessoas. 2) $\mathrm{O}$ direito penal produz racionalizações que legitimam este tratamento diferenciado. 3) O tratamento diferenciado aos inimigos é típico do Estado absoluto e introduz uma contradição permanente entre o direito penal - que admite e legitima o conceito de inimigo - e os princípios constitucionais do Estado de direito.

Por sua vez, Cirino dos Santos (2012) afirma que a distribuição dos seres humanos entre cidadãos e inimigos, legitima a criação de dois sistemas distintos de direito penal. Nessa lógica, o direito penal do inimigo nada mais é que o discurso do direito penal desigual, cujos postulados transitam dos princípios do democrático direito penal do fato e da culpabilidade, para o discriminatório direito penal do autor e da periculosidade.

Refere-se a Jakobs (2004) para quem o conceito de inimigo designa uma realidade ontológica do ser social, identificável por diagnósticos de personalidade perigosa e objeto de prognósticos de criminalidade futura. O tratamento penal do inimigo é, basicamente, a privação de sua liberdade como medida de custódia preventiva, evitando o perigo de fatos futuros. 
Enquanto o cidadão - este ser calculável - atende às expectativas normativas da sociedade, orientando-se conforme um modus vivendi considerado aceitável, desejável ou "normal"; o inimigo - em razão de sua natureza patológica - desafia este modo de viver normalizado e causa desconforto porque aponta para falência da instância da lei, ameaçando a razão e a ordem social.

O que vai distinguir o cidadão do inimigo é a maior ou menor capacidade de assujeitamento à "norma”, não apenas a norma em seu sentido jurídico, mas, sobretudo, no sentido atribuído por Foucault, de norma que define o que é "normal" e aceitável em uma sociedade. Nas palavras de Zaffaroni:

"O estrangeiro (hostis alienigena) é o núcleo troncal que abarca todos os que incomodam o poder, os insubordinados, indisciplinados ou simples estrangeiros que, como estranhos, são desconhecidos e inspiram desconfiança e, por conseguinte, tornam-se suspeitos por serem potencialmente perigosos". (ZAFFARONI, 2006, p. 22).

A insegurança em relação à conduta futura do inimigo é o pretexto para legitimar o exercício diferencial do poder punitivo, calcado na periculosidade, na potencialidade lesiva de sua conduta. A periculosidade é o juízo de previsibilidade que se faz acerca dos atos futuros do inimigo, com base em sua personalidade essencialmente criminosa e tendente à delinquência habitual. Legitima-se, assim, o discurso da prevenção geral positiva para punir.

Ao retirar do inimigo a condição de cidadão, institucionaliza-se o exercício diferencial do poder punitivo pela privação de direitos e garantias constitucionais, na estreita medida do necessário para neutralizar o perigo. Tal medida, de acordo com Zaffaroni (2006), não conhece lei nem limites, porque tais limites são estabelecidos por quem exerce o poder. E como ninguém pode prever o futuro, a incerteza deixa em aberto o juízo de periculosidade, até o momento em que, quem decide, deixa de considerá-lo perigoso. O grau de periculosidade do inimigo depende do juízo subjetivo individualizador de quem exerce o poder.

A busca desesperada do inimigo pelo poder punitivo ocorre em total abandono aos princípios fundadores do Estado Constitucional. Zaffaroni (2006) traz como exemplo o poder punitivo latino-americano, cuja característica marcante é o aprisionamento de pessoas processadas, porém não condenadas. Trata-se de um sistema penal que, calcado na presunção de periculosidade, preferiu operar mediante medida preventiva de contenção, convertendo tudo em privação de liberdade. 
Ocorre que, no caso de delitos considerados graves e dependendo do perfil criminológico de seus autores, a prisão preventiva transforma-se em reclusão perpétua, pois é absurdamente prolongada em processos que se arrastam anos a fio e em cárceres marcados por altíssimos índices de violência, com grandes probabilidades de eliminação física. Os indesejáveis não são punidos por pena formal, mas por prisão cautelar, antes mesmo da condenação.

"Trata-se, na prática, de um direito penal de periculosidade presumida, que é a base para a imposição de penas sem sentença condenatória formal à maior parte da população encarcerada". (ZAFFARONI, 2006, p. 71).

O que se defende, portanto, é a necessidade de investigar as condições de possibilidade que permitiram a consolidação de discursos/saberes acerca dos sujeitos, separando-os nas categorias fixas do normal/anormal, cidadão/inimigo, e a relação que se estabeleceu entre criminologia e subjetividade, para, em um segundo momento, associar tais racionalidades discursivas às práticas de poder resultantes na estigmatização de indivíduos como perigosos e organizadoras do exercício discriminatório do poder punitivo.

\section{NEOLIBERALISMO E SELETIVIDADE PENAL}

Acerca das práticas de poder, Foucault (2008) discorre sobre a influência da racionalidade econômica no sistema de repressão criminal moderno. É que na virada do século XVIII para o XIX, o problema do governo girou em torno do "é ou não interessante agir", em uma verdadeira manipulação governamental dos interesses, fundamentada nas regras naturais do mercado e no cálculo dos custos e benefícios.

Na consolidação da ratio de Estado mínimo, o mercado tornou-se lugar de veridição, pois a economia política atribuiu ao mercado o papel de dizer a verdade em que o governo deveria se orientar. E é a partir dessa verdade que o mercado vai prescrever os mecanismos jurisdicionais sobre os quais deverá se articular.

A questão veridicional influenciou a penalidade moderna e o criminoso passou a ser punido não pelo fato ilícito, mas sim por quem era. A prática penal substituiu a questão: $o$ que você fez? para: quem você é? A função jurisdicional do penal foi secundada ou eventualmente minada pela questão da veridição.

Assim, no século XIX, emerge toda uma cultura política do perigo, marcada pelo aparecimento do crime na literatura policial, por campanhas relativas à doença, à higiene e à 
degeneração do indivíduo, da família, da raça, da espécie humana. Paralelamente, vislumbra-se a extensão dos meios de controle, de pressão, coerção, que vão constituir como que a contrapartida e o contrapeso das liberdades.

A análise econômica dos fenômenos sociais trouxe o problema da criminalidade e da justiça penal para uma questão de economia política. Essa preocupação é percebida nos textos de Beccaria e Bentham, reformadores do século XVIII, em que constam considerações sobre o custo da delinquência, do sistema punitivo e do efeito sensível das penas cruéis na diminuição da taxa de criminalidade.

Filtrando assim toda a prática penal através de um cálculo de utilidade, o que os reformadores buscavam era, precisamente, um sistema penal cujo custo fosse o mais baixo possível. E a solução defendida pelos reformadores foi a legalista, no enaltecimento da lei como necessária ao bom funcionamento do sistema penal. A lei como a solução mais econômica para definir o crime e punir o criminoso.

A proposta do liberalismo é fabricar liberdades conforme o cálculo de seus interesses. E o princípio desse cálculo é a segurança, na medida em que só pode funcionar mediante um certo número de liberdades: de mercado, de produzir, de vender. O problema da segurança se coloca da seguinte forma: proteger o interesse coletivo contra os interesses individuais. A liberdade dos trabalhadores, a doença, a velhice e os acidentes individuais não podem se tornar um perigo para a empresa e para a produção. Era preciso desenvolver estratégias de segurança que zelassem pela mecânica dos interesses. O jogo liberdade e segurança aparece no âmago da nova razão governamental.

O cálculo utilitário, já em meados do século XVIII, toma forma no interior de uma estrutura jurídica e o direito se constrói a partir do critério de utilidade. A lei é o que deve favorecer o jogo, possibilitando que cada um seja sujeito racional, que maximize suas funções de utilidade. A governamentalidade neoliberal apenas reconhece como válida a racionalidade do homo oeconomicus: o ser racional que busca a realização máxima de seus interesses.

Os sujeitos passam a ser valorados na medida de seu capital humano, teoria peculiar ao sistema neoliberal norte-americano e que trouxe as subjetividades para o centro da análise econômica. O homem da troca é empresário de si mesmo, sendo ele próprio o seu capital. Por capital humano, Foucault define como (2009, p.315): “espécies de competência-máquina que vão produzir renda, ou melhor, que vão ser remunerados por renda”. E para formá-lo, em vista das necessidades de uma nação, necessário realizar investimentos, principalmente, sociais. 
Chegou-se, assim, a toda uma análise do ambiente da vida de um ser humano, que desde a infância pode ser calculado e quantificado em termos de possibilidades de investimento. Necessário, pois, repensar certos problemas, como os de saúde e higiene pública, capazes de melhorar ou não o capital humano. Nesse sentido, as políticas sociais estariam também orientadas pelo incremento do capital humano.

Buscou-se racionalizar em termos de custo e benefício relações humanas que até então eram inexploradas pela economia. Mas a aplicação da grade econômica não teve como intuito compreender os processos sociais, e sim, filtrar toda ação estatal em termos de oferta e procura, de eficácia, de custo implicado pela intervenção do poder público no campo do mercado. Em outras palavras, de aferir, em termos de custo e benefício, todas as atividades públicas, inclusive, os programas sociais.

Com base na Teoria do Capital Humano, questiona-se: qual o valor mercadológico do indivíduo taxado como inimigo, portador da condição de "não-pessoa"? Nos termos do neoliberalismo norte-americano, o inimigo, por não convergir com os interesses do capital, não se enquadra na descrição do homo oeconomicus. Seu capital humano é nulo e não vale à pena nele investir, pois não trará retornos econômicos.

Longe de ser o sujeito governamentalizável do laissez-faire/laisser-passer, o inimigo deve ser objeto de intervenção estatal. Ele não responde favoravelmente aos interesses do sistema, nem aceita às variáveis ou responde de forma sistemática às suas modificações. E a hipótese é que o direito penal, enquanto dispositivo de controle das marginalidades, atua como peça-chave para desqualificar a integração cidadã. Atua como instrumento de poder da sociedade neoliberal ao promover a exclusão daqueles que permanecem inertes às oportunidades do mercado.

\section{CONSIDERAÇÕES FINAIS}

Neste artigo, refletimos sobre a necessidade de estudar as racionalidades discursivas legitimantes do tratamento condizente à condição de não-pessoa a certos indivíduos, as quais colocam em funcionamento dois sistemas distintos de direito penal: um destinado aos inimigos, e outro voltado aos cidadãos, favorecendo, com isso, o deslocamento do Estado de direito para o Estado policial.

Acreditamos que, para uma compreensão esclarecedora do problema, é preciso desvelar a relação entre os efeitos dos sentidos impostos por discursos/saberes acerca das personalidades 
perigosas com as práticas de poder, buscando identificar se tais racionalidades legitimam o exercício discriminatório do poder punitivo, com a finalidade de neutralizar todos aqueles que, de alguma forma, ameaçam a estabilidade do contrato social, e ainda, de favorecer o ambiente neoliberal, excluindo os indesejáveis ao capitalismo com base num cálculo de interesse e utilidade.

O "inimigo" precisa ser estudado em referência ao sujeito de direito, buscando entender como este sofreu a influência de saberes normalizadores, em que indivíduos que desviam do critério do "normal" representam a alienação do sujeito de direito, o que, por sua vez, justificaria o tratamento jurídico desigual entre indivíduos conviventes em uma mesma sociedade. Para tal, necessário também o estudo do inimigo nos discursos criminológicos, buscando compreender como se deu o processo de patologização do infrator calcado no paradigma da inferioridade biológica. E sob a perspectiva da Criminologia Crítica, refletir a relação entre punitivismo e subjetividade.

A partir dos novos contextos de poder engendrados pelo neoliberalismo, questionamos em que medida a produção dos rótulos de identificação do perigo e o enaltecimento do discurso de combate à criminalidade pelo controle social (sociedade do risco), são favoráveis aos interesses do mercado, e qual o papel do direito penal como dispositivo estratégico do neoliberalismo em processos de governamentalização jurisdicional-penal da vida.

Finalizamos este artigo chamando atenção para a necessidade de empreendermos uma crítica ao direito penal para além do princípio da soberania, buscando pensá-lo em suas implicações com as relações de dominação e com as técnicas de sujeição polimorfas que as práticas e os saberes jurídicos fazem funcionar. Somente assim será possível pensar em caminhos para a construção de um novo direito penal, resistente aos mecanismos de dominação e sujeição dos sujeitos. 


\section{BIBLIOGRAFIA}

BATISTA, Vera Malaguti. Introdução Crítica à Criminologia Brasileira. Rio de Janeiro: Ed.Revan, 2011.

BATISTA, Vera Malaguti. Adesão subjetiva à barbárie. In: Loic Wacquant e a questão penal no capitalismo neoliberal. Rio de Janeiro: Ed.Revan, 2012.

BECKER, S. Howard. Outsiders. Estudos de Sociologia do Desvio. Rio de Janeiro: Ed.Zahar, 2009.

BECKER, S. Howard. Falando da Sociedade. Rio de Janeiro: Ed.Zahar, 2010.

CASTEL, Robert. O crescimento da incerteza. In: A insegurança social. O que é ser protegido? Petrópolis: Vozes, 2005.

CIRINO DOS SANTOS, Juarez. O direito penal do inimigo - ou o discurso do direito penal desigual. 2012. Disponível em: <http://icpc.org.br/wpcontent/uploads/2012/05/direito_penal_do_inimigo.pdf>. Acesso em: 20 nov.2015.

DELEUZE, Gilles. Controle e Devir. In: Conversações. São Paulo: Ed. 34, 2008.

DELUCHEY, Jean-François Y; BRITO, Michelle Barbosa de. Políticas públicas e soberania popular: por uma refundação democrática da segurança pública. In: Direito e Desenvolvimento. São Paulo: Editora Método, 2013.

FONSECA, Márcio Alves de. Michel Foucault e o Direito. São Paulo: Ed. Max Limonad, 2002.

FOUCAULT, Michel. O Sujeito e o Poder. In: DREYFUS, Hubert; RABINOW, Paul. Michel Foucault - Uma trajetória filosófica: para além do estruturalismo e da hermenêutica. Rio de Janeiro: Forense Universitária, 1995.

FOUCAULT. Michel. Arqueologia do saber. Rio de Janeiro. Forense, 2000.

FOUCAULT, Michel. Nascimento da Biopolítica. São Paulo: Ed. Martins Fontes, 2008.

FOUCAULT, Michel. Segurança, Território, População. São Paulo: Ed. Martins Fontes, 2009.

FOUCAULT, Michel. Em Defesa da Sociedade. São Paulo: Ed. Martins Fontes, 2010.

FOUCAULT, Michel. História da Loucura. São Paulo: Ed. Perspectiva, 2012.

GARAPON, Antoine. La Raison du moindre État. Le néolibéralisme et la justice. Paris: Odile Jacob, 2010.

RAUTER, Cristina. Criminologia e Subjetividade no Brasil. Rio de Janeiro: Ed. Revan, 2003.

Revista de Criminologias e Políticas Criminais | e-ISSN: 2526-0065 | Curitiba | v. 2 | n. 2 | p. 99 - 116 | Jul/Dez. 2016. 
RIBEIRO, Felipe F.C. Genealogia dos homens perigosos: o dispositivo psiquiátrico criminal na contemporaneidade. 2013. Dissertação de Mestrado (Programa de Pós-Graduação em Psicologia). Universidade Federal do Pará.

WACQUANT, Loïc. Insegurança social e surgimento da preocupação com a segurança. In: Panóptica - Direito, Sociedade e Cultura, ano 3, nº 19. julho-outubro 2010.

WACQUANT, Loïc. As Prisões da Miséria. Rio de Janeiro: Ed. Zahar, 2001.

ZAFFARONI, Raúl Eugenio. O Inimigo no Direito Penal. Rio de Janeiro: Ed. Revan, 2006. 